\title{
Interview: Andrew Gouldson
}

\author{
The new Centre for Climate Change Economics and Policy at the London School of Economics \\ and the University of Leeds launches 27 January. Andrew Gouldson — who will co-direct the \\ centre with Judith Rees, under chairman Lord Nicholas Stern - argues that researchers should \\ be zooming in on regional change and talking to local stakeholders while the world makes the \\ push for a global climate deal. Interview by Anna Barnett.
}

What's your vision for the centre? I think there is a need to move beyond thinking about climate science and climate policy at the global level and to scale it down to focusing on national, regional and local responses, whether that's in terms of mitigation or adaptation. And there are all sorts of research and policy challenges associated with that.

Part of the rationale for the centre was to draw people with the relevant expertise - from international relations to politics and economics - into this area.

The London School of Economics and the University of Leeds are jointly hosting the centre. Who else is involved?

The centre is primarily funded by the Economic and Social Research

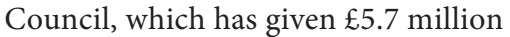
for the first five years and will hopefully fund another five after that. We have additional sponsorship, about another $£ 3$ million, from Munich Re, the insurance company, to fund a stream on climate change finance. This will specifically look at the links between climate change predictions and the role of the insurance industry.

\section{There is a need to move beyond thinking about climate science and climate policy at the global level and to scale it down to focusing on national, regional and local responses.}

\section{What kinds of challenges will the centre address?}

To give you an example, some of the water companies in the UK have been asking climate scientists what their investments should be for the next 50 years. Some of the climate models say it could be drier, and therefore they would need to put in drought-resistant water supply systems and reservoirs; others say it's likely to be much stormier, in which case they would need to invest in much more robust water systems. So the science doesn't tell these companies exactly what they need to do, and we need to find ways of working with them to understand what they need from climate science.

Another big challenge is identifying vulnerability hot spots. One of the projects, for example, will look at China. By comparing regions in China that historically have been very vulnerable to drought with those that have been drought-resistant, we can get an idea of the policies needed to make the vulnerable regions more resilient.

Global modelling, perhaps necessarily, tends to be a very expert-led process. In every other area, once you get down to a local level you need more open, inclusive, participatory approaches. And that's a major challenge, I think. We're working with a range of partners in various government bodies to conduct applied, policy-relevant research, which builds both their capacity and ours - ours to do good research, and theirs to use that research to take better decisions on climate change.

One of the aims of the new centre is to identify how industrialized countries can reduce emissions efficiently. How do you think the global recession will affect our ability to mitigate and adapt to climate change?

In the short term an economic slowdown clearly will reduce demand for energy and emissions of greenhouse gases, but it also means that suddenly investments in renewables are less attractive and more risky than they were previously. So, medium to long term, it's possible that the recession will really slow things down on the mitigation front.

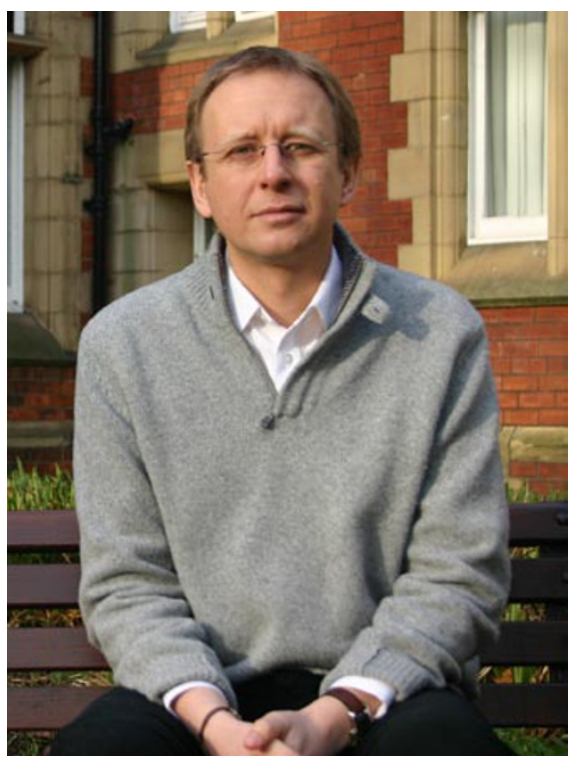

That said, new policies are coming through that are creating markets for renewables. The UK's 80 per cent reduction commitment, for example, means that we're locked in now to a huge expansion in renewables in the next 10 to 12 years. But whether we have the capacity to do that, given all the economic restrictions, is another thing.

On the adaptation side, it's really a mixed picture. So much is dependent on the UN negotiations taking place at the end of this year in Copenhagen and the adaptation fund that might be created there. But adaptation is still very much a second player in all of this. The levels of investment, but also the state of thinking on policy interventions around adaptation, are not quite as advanced as they could be.

Another of the centre's aims is examining how to overcome the deadlock in international climate talks. How are things shaping up on agreeing a global deal? The next phase, for some countries at least, is going to be about designing the 
policies that deliver on their existing obligations. The European Union, which adopted a whole raft of new policies in December, and the UK, which adopted its own climate change act in the autumn, have provisions that say, 'we will commit to this unilaterally, but if there's an international agreement we'll commit to much more.'

Whether we will get there or not, I don't know. I think people are, on balance, a little bit disappointed with what happened at Poznan in December and are thinking that there will be quite an amount of brinksmanship before Copenhagen next December.
At the national level, I think Britain's been very proactive indeed. The government has been quite brave signing up to this medium- to longterm target which is really quite ambitious. But I don't think there's a public understanding, or possibly even a public acceptance, of what a low-carbon economy might look like - one which is $60,70,80$ per cent decarbonized.

\section{Does that make it less likely that the} policy will actually come through with results?

In the next 10 to 15 years, not necessarily, because there are lots of mitigation options that are relatively affordable and technologically viable. I think the question is what happens in the phase after that. Is there a political appetite to do some really quite painful things which would involve some powerful people or parties losing out? I think there's a need now, in the next few years, to build some sort of broad consensus on the need to shift towards a low-carbon economy.

Published online: 22 January 2009

\section{doi:10.1038/climate.2009.7}

Anna Barnett is assistant editor and copy editor of Nature Reports Climate Change.

\section{naturechINA 然 $_{\text {i }}$}

Your one-stop web portal, highlighting significant research from scientists in mainland China and Hong Kong. Visit www.nature.com/nchina

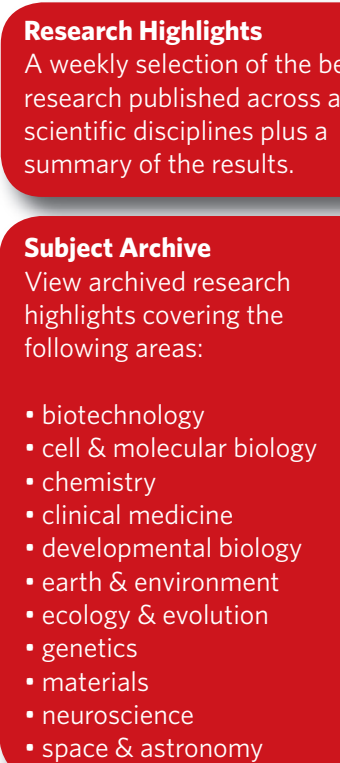

- space \& astronomy

\section{Jobs}

Keep informed about the

latest job openings in cancer

research at the AstraZeneca

Innovation Center China (ICC)
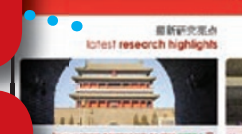

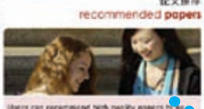
Astrazeneces
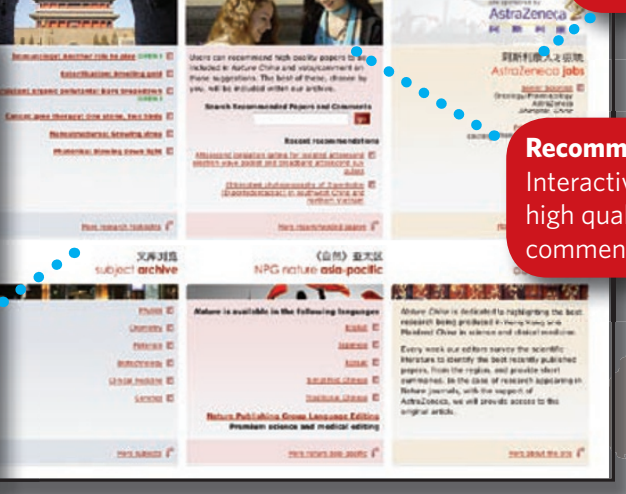

section to recommend

gh quality papers and vote/

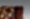

Supported by

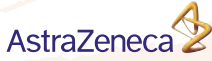

阿 斯 利 康 